\title{
Development of Hearing Aid Gain for Korean Hearing Impaired version 2.0 Considering Levels and Spectra of Korean Conversational Speech, and Preferred Gain
}

\author{
Kyoungwon Lee ${ }^{1,2}$, Soohyun Ahn ${ }^{1,2}$, Hyeryeong Jo $\mathrm{J}^{1,2}$ \\ 'Department of Audiology and Speech-Language Pathology, Hallym University of Graduate Studies, Seoul, Korea \\ ${ }^{2}$ HUGS Center for Hearing and Speech Research, Seoul, Korea
}

\author{
Received: October 5, 2020 \\ Revised: November 4, 2020 \\ Accepted: November 17, 2020 \\ Correspondence: \\ Kyoungwon Lee, PhD \\ Department of Audiology and \\ Speech-Language Pathology, \\ Hallym University of Graduate Studies, \\ 427 Yeoksam-ro, Gangnam-gu, \\ Seoul 06197, Korea \\ Tel: +82-2-2051-4951 \\ Fax: +82-2-3453-6618 \\ E-mail: hearing1004@naver.com
}

\begin{abstract}
Purpose: This study aimed to report the development of Hearing Aid Gain for Korean Hearing Impaired version 2.0 (HAG-K v2.0), the Korean-type hearing aid fitting formula to improve the satisfaction of hearing aids and the communication ability of the Korean hearing impaired. Methods: HAG-K v2.0 was compared to NAL-NL2 with real-ear insertion gain (REIG) of the Korean hearing impaired, which was produced by considering most comfortable level and uncomfortable level, the levels and spectra of Korean conversational speech, band importance function, and preferred gain. Results: When REIG produced from HAG-K v2.0 was compared to NAL-NL2, it resulted low at HTL 40 and $80 \mathrm{~dB} \mathrm{HL}$ and the compression threshold of HAG-K v2.0 was higher in all HTL compared to NAL-NL2. And the compression ratio was high at HTL $40 \mathrm{~dB} H \mathrm{HL}$ for NAL-NL2 and at $80 \mathrm{~dB}$ HL for HAG-K v2.0. Conclusion: HAG-K v2.0 developed in this study is the initial version of the Korean-type hearing aid fitting formula considering the characteristics of Korean conversational speech levels, spectra and preferred gain. With the systematic corrections and supplements for HAG-K V2.0 in the future, the Korean hearing impaired would benefit from this formula in electroacoustic control of the hearing aids.
\end{abstract}

Key Words: Hearing Aid Gain for Korean Hearing Impaired version 2.0, Hearing aid, Fitting formula, Korean, Hearing Impaired.

\section{INTRODUCTION}

난청인이 착용하는 보청기의 입력 음압레벨(sound pressure level, SPL)에 따른 이득과 주파수반응곡선의 초기 조절은 주 로 보청기적합공식(hearing aid fitting formula)을 기준으로 조절한다. 선형 증폭기에서 보청기적합공식은 $1 / 2$ 이득법(a half gain rule)을 토대로 Berger, prescription of gain and output (POGO), Libby 1/3 또는 2/3, National Acoustic Laboratories (NAL), desired sensation level (DSL) 등이 개발되었다. 이후 개발된 비선형 증폭기에서는 작은, 보통, 큰 소리에 대한 이득 을 효과적으로 각각 조절하기 위해 figure 6 (Fig. 6), independent hearing aid fitting forum (IHAFF), National Acoustic Laboratories-non-linear 1 or 2 (NAL-NL1 또는 2), desired

(c) This is an Open Access article distributed under the terms of the Creative Commons Attribution Non-Commercial License (https://creativecommons.org/licenses/by-nc/4.0) which permits unrestricted non-commercial use, distribution, and reproduction in any medium, provided the original work is properly cited. sensation level input/output (DSL I/O) 등의 보청기적합공식 이 개발되어 사용하고 있다. 근래에 들어서 보청기 제조사들 또한 자사의 보청기적합공식을 개발하여 보청기의 다양한 전 기음향의 초기 조절에 사용하고 있다.

보청기적합공식의 산출에 영향을 주는 요소는 청력역치레벨 (hearing threshold level, HTL), 쾌적강도레벨(most comfortable level, MCL) 및 불쾌강도레벨(uncomfortable level, UCL), 상향차폐(upward spread of masking) 등의 청지각적 요소, 연 령에 따른 외이도의 용적, 보청기의 형태 등의 실이대커플러차 (real-ear to coupler difference), 대화음의 강도와 스펙트럼, 대역중요함수(band importance function) 등 어음의 특성이 있다(Byrne \& Dillon, 1986; Byrne et al., 2001; Cox, 1995; Johnson \& Dillon, 2011; Kiessling et al., 1996; Killion \& Fikret-Pasa, 1993).

하지만 Lee \& $\operatorname{Kim}(2011)$ 의 연구에서 한국어의 음향적 특성 이 미국, 유럽 등 서구에서 사용하는 어음(speech sound)과 서 
로 다르다는 점을 들어 한국 난청인이 사용하는 보청기의 조절 에 필요한 보청기적합공식 개발의 필요성을 보고하였다. 이후 한국어의 음향적 특성에 대한 연구에서 Noh \& Lee(2012)는 장기평균어음스펙트럼(long-term average speech spectrum), Han \& Lee(2020)는 한국어 대화음의 강도 및 이에 따른 스펙 트럼이 외국어(International Electrotechnical Commission, 2012)와 차이가 있음을 보고하였다. 그리고 Bang \& Lee(2020) 또한 한국 난청인의 선호이득이 NAL-NL2 등 외국의 보청기 적합공식과 차이가 있음을 보고하여 한국형 보청기적합공식 의 필요성을 보고하였다.

최근 한국에서의 보청기적합공식 관련 연구를 살펴보면 Kim \& Lee(2019)는 다채널 보청기의 압축역치(compression threshold, CT)를 55, 65, $75 \mathrm{~dB}$ SPL로 설정했을 때 55 및 65 $\mathrm{dB}$ SPL의 CT에서 잡음환경에서의 초성자음인지도가 높게 나 타나지만, $55 \mathrm{~dB}$ SPL에서는 65 및 $75 \mathrm{~dB}$ SPL의 CT에 비해 잡 음을 크게 느낀다고 하였다. 그리고 Han et al.(2017)은 해제시 간 관련 연구에서 한국에서 개발한 다채널 보청기 시제품 (prototype)의 CT를 31과 $61 \mathrm{~dB}$ SPL로 설정했을 때 문장인지 역치, 음량의 크기, 날카로움, 명료성, 배경잡음의 크기에는 차 이가 나타나지 않았다고 보고하였다. 같은 연구에서 해제시간 (release time)을 50과 $500 \mathrm{~ms}$ 로 설정했을 때 음량, 음질, 배경 잡음에는 차이가 나타나지 않았으나 빠른 해제시간에서 명료 도가 더 높게 나타났다고 보고하였다. 그리고 Jeong \& Lee(2018)의 연구에서는 70과 $600 \mathrm{~ms}$ 에 비해 $250 \mathrm{~ms}$ 의 해제 시간에서 잡음 환경에서의 문장인지도가 높게 나타났다고 보 고하였다. 그리고 Jin et al.(2017)과 Han et al.(2017)은 한국어 의 음향 특성과 음량증가(loudness growth), 평균 대화음레벨 (conversational speech level), 폐쇄효과(occlusion effect)를 고 려하여 한국형 보청기적합공식인 Hallym Audiology Institute-version 1 (HAI-v1)을 보고하였으나 현재까지 상용화되 지는 않고 있다.

이에 본 연구에서는 한국어 대화음레벨과 스펙트럼 및 선호 이득 등 한국어의 음향적 특징과 한국인의 심리음향적 특성을 고려하여 새로운 한국형 보청기적합공식인 한국 난청인을 위한 보청기이득 버전 2.0 (Hearing Aid Gain for Korean Hearing Impaired version 2.0, HAG-K v2.0)을 개발하여 이를 보고하 고자 하였다. 본 연구를 통하여 선행 연구에서 개발한 HAIv1(Jin et al., 2017; Han et al., 2017)을 보완하고, 청능재활 현 장에서 한국 난청인이 착용한 보청기 이득의 효과적인 조절 그 리고 난청인의 어음인지도, 의사소통 능력 그리고 보청기의 만 족도를 개선하는데 도움을 주고자 하였다.

\section{MATERIALS AND METHODS}

\section{연구 장비}

HAG-K v2.0은 난청인의 MCL과 UCL의 변화는 Park \& Lee(2013), 한국어 대화음의 스펙트럼과 강도는 Han \& Lee (2020), 대역중요함수는 Lee \& Kim(2012)과 Jin et al.(2016), 선 호하는 CT와 이득은 Kim \& Lee(2019), Han \& Lee(2020) 및 Bang \& Lee(2020)를 고려하여 HTL에 따른 실이삽입이득 (real-ear insertion gain, REIG)을 산출하였다.

\section{HAG-K v2.0의 개발절차}

HAG-K v2.0에서 입력 SPL 50 dB에 대한 REIG (REIG for $50 \mathrm{~dB}$ SPL input, REIG50), $65 \mathrm{~dB}$ 에 대한 REIG (REIG for 65 dB SPL input, REIG65), 80 dB에 대한 REIG (REIG for $80 \mathrm{~dB}$ SPL input, REIG80)의 산출 절차는 다음과 같다.

첫째, 비선형 증폭방식의 작은(soft), 보통(moderate), 큰 (loud) 소리의 입력 SPL은 $0.125 \mathrm{kHz}$ 에서 $8.0 \mathrm{kHz}$ 까지 모든 $1 / 2$ 옥타브 주파수에서 $50,65,80 \mathrm{~dB} \mathrm{SPL}$ 을 기준으로 하였다.

둘째, 이득은 모든 $1 / 2$ 옥타브 주파수에서 REIG50, REIG65, REIG80을 각각 산출하였다.

셋째, $1.5 \mathrm{kHz}$ 이하의 주파수에서 REIG는 Bang \& Lee (2020)의 연구 결과인 한국 감각신경성 난청인의 선호이득을 기준으로 REIG를 산출하였으며, CT는 Kim \& Lee(2019)와 Han \& Lee(2020)의 연구 결과를 기준으로 $60 \mathrm{~dB} \mathrm{SPL}$ 부근으 로 설정하였다.

넷째, 압축비율(compression ratio, CR)은 기본적으로 Park \& Lee(2013)의 HTL에 따른 MCL과 UCL의 변화를 사용하였다. 하지만 HTL이 증가할수록 역동범위가 좁아지는 감각신경성 난 청인의 특징을 감안하여 $\mathrm{HTL}$ 을 $50 \mathrm{~dB} \mathrm{HL}$ 이하와 $55 \mathrm{~dB} \mathrm{HL}$ 이상으로 구분하여 REIG를 산출하였다.

다섯째, 폐쇄효과(occlusion effect)는 고주파수 대역에 영향을 주지 않으므로 $2.0 \mathrm{kHz}$ 이상의 주파수에서 REIG50, REIG65, REIG80은 모두 $1.5 \mathrm{kHz}$ 와 같게 나타나도록 산출하였으며, 음 향피드백시스템의 작동여부에 대한 사항은 고려하지 않았다.

여섯째, HTL이 $20 \mathrm{~dB}$ HL 이하인 경우 모든 입력 SPL에 대 한 REIG는 모든 $1 / 2$ 옥타브 주파수에서 ' 0 '으로 처리하였다.

일곱째, $0.25 \mathrm{kHz}$ 에서 $1.5 \mathrm{kHz}$ 까지의 기울기(slope; dB/octave)는 Bang \& Lee(2020)의 선호이득과 $1 \mathrm{kHz}$ 부근에서 높 게 나타나는 대역중요함수(Lee \& Kim, 2012; Jin et al., 2016) 를 고려하여 산출하였다.

HAG-K v2.0에서 $1.0 \mathrm{kHz}$ 의 HTL에 따른 REIG50, REIG65 및 REIG80에 대한 기울기는 $50 \mathrm{~dB} \mathrm{HL}$ 이하에서는 $0.68,0.52$ 및 $0.33 \mathrm{~dB}$ /octave, $55 \mathrm{~dB}$ HL 이상에서는 $0.56,0.52$ 및 0.33 
$\mathrm{dB} /$ octave이었다. Table 1은 $1.0 \mathrm{kHz}$ 의 HTL $50 \mathrm{~dB}$ HL 이하 와 $55 \mathrm{~dB}$ HL 이상에서 입력 SPL $50,65,80 \mathrm{~dB}$ 에 대한 REIG 를 산출하기 위한 수식을 나타내었다.

\section{$\mathrm{HAG}-\mathrm{K}$ v2.0과 NAL-NL2의 비교}

$\mathrm{HAG}-\mathrm{K}$ v2.0에서 산출한 REIG50, REIG65 및 REIG80은 NAL-NL2 (version 2.15)에서 산출한 REIG와 비교하였다. NAL-NL2의 REIG는 HAG-K v2.0과 마찬가지로 입력 SPL $50 \mathrm{~dB}$ 에 대한 NAL-NL2의 REIG (REIG50 for NAL-NL2, REIG50-N), $65 \mathrm{~dB}$ 에 대한 NAL-NL2의 REIG (REIG65 for NAL-NL2, REIG65-N), 80 dB에 대한 NAL-NL2의 REIG (REIG80 for NAL-NL2, REIG80-N)를 각각 산출하였다.

\section{RESULTS}

모든 옥타브 주파수에서 40,60, $80 \mathrm{~dB} \mathrm{HL}$ 의 HTL을 입력 했을 때, HAG-K v2.0 (REIG50, REIG65 및 REIG80)과

Table 1. Formula used to calculate REIGs of $1.0 \mathrm{kHz}$ at input sound pressure level of 50, 65, $80 \mathrm{~dB}$ in HAG-K v2.0

\begin{tabular}{cl}
\hline HTL $\leq 50 \mathrm{~dB} \mathrm{HL}$ & \multicolumn{1}{c}{ HTL $\geq 55 \mathrm{~dB} \mathrm{HL}$} \\
\hline REIG50 $=0.56(\mathrm{HTL})-11.2$ & REIG50 $=0.68(\mathrm{HTL})-18$ \\
REIG65 $=0.52(\mathrm{HTL})-10.5$ & REIG65 $=0.52(\mathrm{HTL})-10.5$ \\
REIG80 $=0.33(\mathrm{HTL})-6.6$ & REIG80 $=0.33(\mathrm{HTL})-6.5$ \\
\hline
\end{tabular}

HAG-K v2.0: Hearing Aid Gain for Korean Hearing Impaired version 2.0, HTL: hearing threshold level, REIG: real-ear insertion gain
NAL-NL2 (REIG50-N, REIG65-N 및 REIG80-N)에 의해 산출한 REIG는 Figure 1과 같다. Figure 1에서 이득과 0.25 $\mathrm{kHz}$ 에서 $0.5 \mathrm{kHz}$ 까지의 기울기 및 $\mathrm{CT}$ 와 $\mathrm{CR}$ 을 살펴보면 다음 과 같다.

\section{이득과 주파수반응곡선}

$\mathrm{HAG}-\mathrm{K}$ v2.0에서 산출한 보통 크기의 대화음레벨 $65 \mathrm{~dB}$ SPL에 대한 REIG65는 HTL이 $60 \mathrm{~dB}$ HL(Figure 1B)일 때는 $1.0 \mathrm{kHz}$ 에서 $3.0 \mathrm{kHz}$ 그리고 $40 \mathrm{~dB}$ HL(Figure 1C)일 때는 1.0 $\mathrm{kHz}$ 이하의 주파수에서 NAL-NL2와 비슷하게 나타났다. 나 머지 모든 주파수에서 HAG-K v2.0의 REIG는 NAL-NL2에 비해 낮게 나타났다. HTL이 $80 \mathrm{~dB}$ HL(Figure 1A)일 때는 모 든 주파수에서 $\mathrm{HAG}-\mathrm{K}$ v2.0의 REIG가 NAL-NL2에 비해 낮 게 나타났다. 그리고 $0.25 \mathrm{kHz}$ 에서 $1.0 \mathrm{kHz}$ 까지의 기울기는 $\mathrm{HTL}$ 40, 60 및 $80 \mathrm{~dB}$ HL에서 2.0, 4.1 및 $6.1 \mathrm{~dB} /$ octave로 각각 나타나 HTL $60 \mathrm{~dB}$ 와 $80 \mathrm{~dB}$ HL에서 $\mathrm{HAG}^{-K}$ v2.0이 NALNL2에 비해 높게 나타났다(Figure 1).

\section{CT와 CR}

Figure 1에서 50, 65 및 $80 \mathrm{~dB}$ 의 입력 SPL에 따른 REIG의 차이를 토대로 $\mathrm{CT}$ 와 $\mathrm{CR}$ 을 유추하여 살펴보면, $\mathrm{CT}$ 는 모든 HTL에서 HAG-K v2.0이 NAL-NL2에 비해 높게 나타났다. 그리고 $\mathrm{CR}$ 은 $\mathrm{HTL} 60 \mathrm{~dB} \mathrm{HL}$ 에서는 $\mathrm{HAG}^{-K}$ v2.0과 NALNL2가 비슷하게 나타났으나 $40 \mathrm{~dB}$ HL에서는 NAL-NL2가,
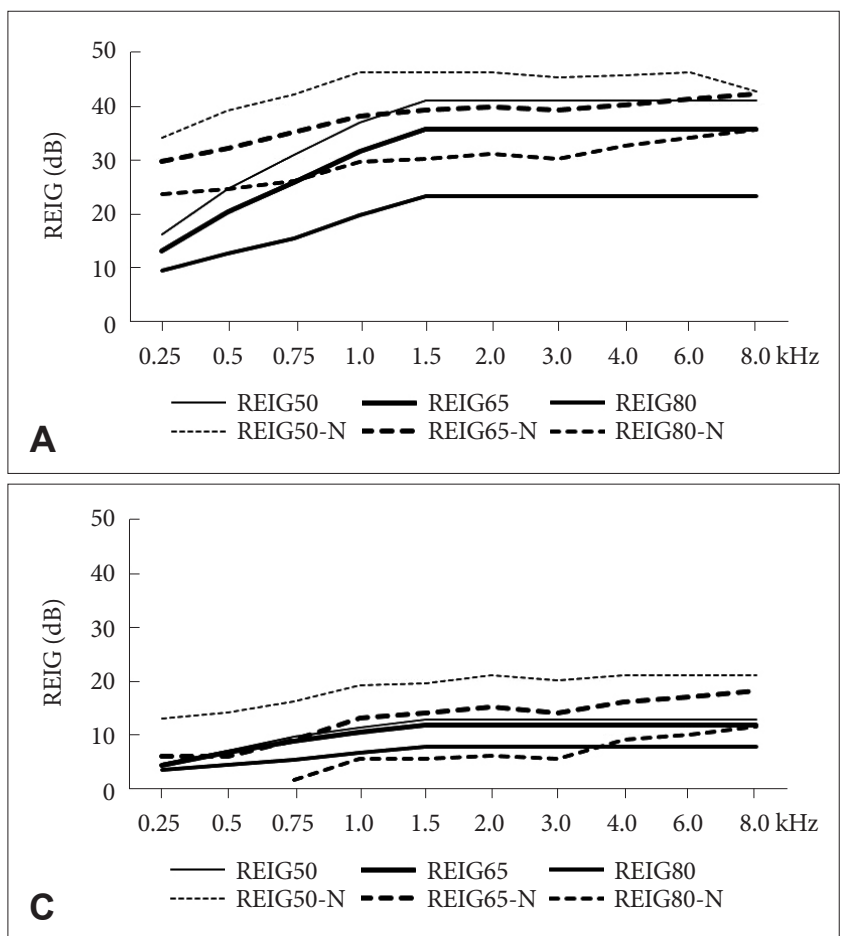

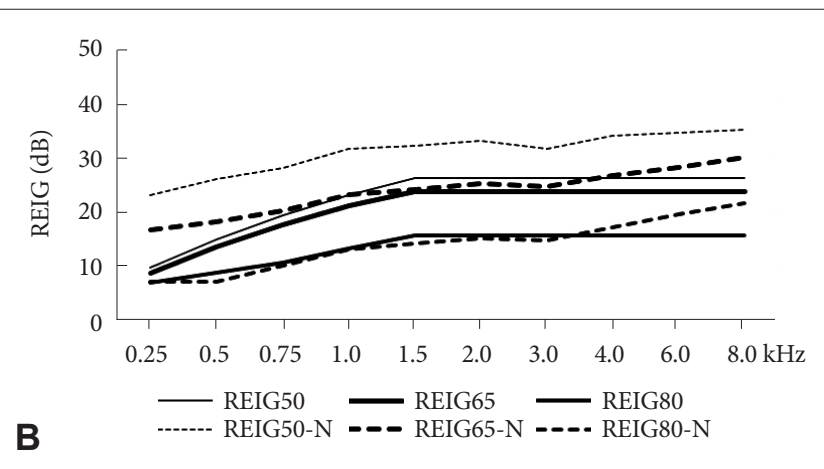

Figure 1. REIG calculated at HTL $80 \mathrm{~dB} H L(A), 60 \mathrm{~dB} H L(B), 40 \mathrm{~dB}$ HL (C) for HAG-K v2.0 and NAL-NL2. REIG50, REIG65, REIG80 are REIGs of HAG-K v2.0, and REIG50-N, REIG65-N, REIG80-N are REIGs of NAL-NL2. NAL-NL2: National Acoustics Laboratories-NonLinear 2. REIG: real-ear insertion gain, HTL: hearing threshold level, HAG-K v2.0: Hearing Aid Gain for Korean Hearing Impaired version 2.0 . 
$80 \mathrm{~dB}$ HL에서는 HAG-K v2.0이 높게 나타났다. CR은 전체적 으로 $1.0 \mathrm{kHz}$ 이하의 저주파수로 갈수록 $\mathrm{HAG}-\mathrm{K}$ v2.0의 CR 이 낮아지는 경향을 보였으나, NAL-NL2는 모든 주파수에서 비슷하게 나타났으며, $60 \mathrm{~dB}$ HL 이상에서는 HTL과 관계없이 $\mathrm{CR}$ 이 비슷하게 나타났다.

\section{DISCUSSIONS}

본 연구는 한국어의 대화음레벨의 강도와 이에 따른 스펙트 럼(Han \& Lee, 2020), 한국 난청인의 선호이득(Bang \& Lee, 2020), 전기음향의 조절(Jeong \& Lee, 2018; Kim \& Lee, 2019)에 따른 어음의 인지도가 외국어와 차이가 나타났다는 것 에 근거하여 HAG-K v2.0을 개발하였다. 본 연구에서 산출한 REIG를 통하여 보통 대화음레벨의 이득(REIG65), CT 및 CR 을 중심으로 살펴보면 다음과 같다.

\section{REIG65}

모든 $1 / 2$ 옥타브 주파수에서 HTL이 $60 \mathrm{~dB}$ 일 때 $\mathrm{HAG}-\mathrm{K}$ $\mathrm{v} 2.0$ 에서 산출한 보통 크기의 대화음레벨 $65 \mathrm{~dB}$ SPL에 대한 REIG65는 $1.5 \mathrm{kHz}$ 에서 $3.0 \mathrm{kHz}$ 까지는 NAL-NL2와 비슷하 게 나타났으나, $1.5 \mathrm{kHz}$ 이하와 $3.0 \mathrm{kHz}$ 이상의 주파수에서는 NAL-NL2가 높게 나타났다. Han \& Lee(2020)의 연구에서 보 통 대화음레벨 65 백분위수(percentile)의 강도는 $64.74 \mathrm{~dB}$ SPL로 International Electrotechnical Commission(2012)와 비슷하게 나타났으나, 주파수 스펙트럼은 $0.25 \mathrm{kHz}$ 에서 1.6 $\mathrm{kHz}$ 까지 한국어음이 외국어음에 비해 높은 강도로 나타났다. Lippmann et al.(1981), Keidser et al.(2011)의 연구에서 보청기 의 이득은 보통 크기의 대화음레벨을 난청인의 $\mathrm{MCL}$ 까지 증폭 하는데 필요한 증폭량 또는 음량증가를 고려하여 결정한다고 하였다. 본 연구에서의 REIG65를 NAL-NL2와 비교했을 때 $1.5 \mathrm{kHz}$ 에서 $3.0 \mathrm{kHz}$ 주파수 대역에서는 비슷하게 나타났으나 $0.25 \mathrm{kHz}$ 에서 $1.6 \mathrm{kHz}$ 의 주파수 대역에서 낮게 나타난 근거로 볼 수 있다.

그리고 $0.25 \mathrm{kHz}$ 에서 $1.0 \mathrm{kHz}$ 까지 $\mathrm{HAG}-\mathrm{K}$ v 2.0 에서 산출 한 REIG65의 기울기는 NAL-NL2에 비해 높게 나타났다. Han \& Lee(2020)의 연구에서 한국어의 65 백분위수에 대한 주파수 스펙트럼은 $0.25 \mathrm{kHz}$ 에서 $1.6 \mathrm{kHz}$ 까지 외국어음에 비 해 높은 강도로 나타났다. 따라서 HAG-K v2.0은 $1.0 \mathrm{kHz}$ 이 하의 주파수에서의 이득을 적게 산출한 것으로 나타났다.

그러나 HTL $40 \mathrm{~dB}$ 와 $80 \mathrm{~dB}$ HL에서의 REIG65는 모든 $1 / 2$ 옥타브 주파수에서 NAL-NL2에 비해서 낮게 나타났다. 한국 (Han \& Lee, 2020)과 해외(International Electrotechnical Commission, 2012)의 연구에서 작은 대화음레벨인 30 백분위
수는 한국어음이 $59.67 \mathrm{~dB} \mathrm{SPL}$, 외국어음은 $55 \mathrm{~dB} \mathrm{SPL}$ 로 보 고하여 30 백분위수가 더 높은 한국인의 REIG가 더 낮은 것 으로 보인다. 그리고 큰 대화음레벨인 99 백분위수는 한국어음 이 $79.07 \mathrm{~dB}$ SPL과 외국어음은 $80 \mathrm{~dB} \mathrm{SPL}$ 로 보고하여 큰 차 이는 나타나지 않았다. 하지만 $5.0 \mathrm{kHz}$ 이하의 주파수 스펙트 럼에서 한국어음의 강도가 외국어음에 비해 높게 나타나는 것 을 고려하면 HAG-K v2.0의 REIG가 NAL-NL2에 비해 낮게 나타나는 이유가 될 것이다.

$4.0 \mathrm{kHz}$ 이상의 주파수에서 40, 60, $80 \mathrm{~dB}$ HTL 모두 $\mathrm{HAG}^{-}$ $\mathrm{K}$ v2.0의 REIG가 NAL-NL2에 비해 낮게 나타났다. 그 이유는 $\mathrm{HAG}-\mathrm{K}$ v2.0의 REIG 산출 시 보청기의 음질, 만족도, 단어인 지도 등 한국 난청의 선호이득(Bang \& Lee, 2020)을 고려하였 기 때문이다. 그리고 Figure 2는 Bang \& Lee(2020)의 연구와 $\mathrm{HAG}-\mathrm{K} v 2.0$ 을 비교한 것으로 같은 HTL에서 $3.0 \mathrm{kHz}$ 이상 의 주파수에서는 선호이득과 HAG-K v2.0 간의 차이를 나타 내고 있다. 그 이유는 Bang \& Lee(2020)의 연구에서 보청기의 전기음향적 조절 시 음질 및 착용 만족도를 위주로 조절하였으 며, 개방(non-occluded)형과 폐쇄(occluded)형 등 환기구의 직 경, 보청기 형태 및 음향피드백제어시스템의 영향을 고려하지 않 았기 때문이다. 개방형 보청기의 경우 음향피드백제어시스템의 작동으로 인해 고주파수의 이득이 저하되는 경향이 있다(Aazh et al., 2012)고 하였는데, HAG-K v2.0에서는 한국형 보청기적 합공식의 초기 버전으로 환기구를 설치한 보청기에서 나타나 는 음향피드백에 대한 영향을 고려하지 않아서 고주파수의 이 득은 저하되지 않도록 산출하였다.

\section{CT와 $\mathrm{CR}$}

$50,65,80 \mathrm{~dB}$ 의 입력 SPL의 REIG를 토대로 HAG-K v2.0 과 NAL-NL2의 CT를 비교해보면, HTL 40, 60, 80 dB HL에

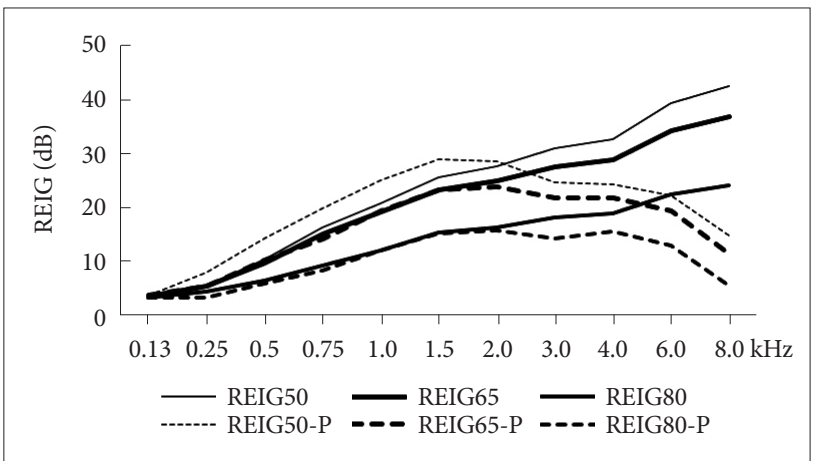

Figure 2. REIG calculated from HAG-K v2.0 and preferred gain of Korean hearing impaired (Bang \& Lee, 2020). REIG50, REIG65, REIG80 are REIGs of HAG-K v2.0, and REIG50-P, REIG65-P, REIG80-P are REIGs of preferred gain of Korean hearing impaired (Bang \& Lee, 2020). REIG: real-ear insertion gain, HAG-K v2.0: Hearing Aid Gain for Korean Hearing Impaired version 2.0. 
서 HAG-K v2.0의 CT가 모든 주파수에서 NAL-NL2에 비해 높게 나타났다. 이는 한국어 30 백분위수의 대화음레벨이 외국 어음에 비해 $5 \mathrm{~dB}$ 정도 높다는 연구(Han \& Lee, 2020) 결과로 비추어볼 때 REIG50은 외국어에 비해 낮게 산출해도 대화 능 력은 문제가 없을 것으로 보인다. 그리고 Barker et al.(2001), $\operatorname{Souza}(2002)$ 의 연구에서 기술하였듯이 비선형 증폭기의 낮은 $\mathrm{CT}$ 는 주변의 잡음을 어음과 함께 증폭하여 신호대잡음비(signal-to-noise ratio) 및 음질을 나쁘게 할 우려가 있다. 또한 Barker \& Dillon(1999), Barker et al.(2001)의 연구에서 중고도 의 감각신경성 난청인은 대화음 레벨인 $65 \mathrm{~dB}$ SPL 부근의 CT 를 선호한다고 보고하였다. 따라서 HAG-K v2.0에서 산출한 REIG50 즉, $60 \mathrm{~dB} \mathrm{SPL}$ 의 CT는 신호대잡음비 및 음질의 개선 에 유용할 것으로 볼 수 있다.

HAG-K v2.0에서 산출한 CR을 NAL-N2와 비교했을 때 REIG65에서는 비슷하게 나타났다. 그러나 HTL $40 \mathrm{~dB}$ HL에 서는 NAL-NL2, $80 \mathrm{~dB}$ HL에서는 HAG-K v2.0의 CR이 더 높게 나타났다. 비선형 증폭기에서의 $\mathrm{CR}$ 은 역동범위 즉, $\mathrm{HTL}$ 과 $\mathrm{UCL}$ 의 차이에 의해 결정되는데(Souza, 2002) HAG-K v2.0은 HTL이 높을수록 역동범위가 좁아지는 연구(Park \& Lee, 2013)를 반영한 것이다. 그리고 Boike \& Souza(2000)는 잡음 환경에서의 높은 $\mathrm{CR}$ 은 경도에서 중도의 감각신경성 난청 인이 착용하는 보청기의 음질에 나쁜 영향을 줄 수 있다고 보고 하여 HTL이 $40 \mathrm{~dB}$ HL일 때 HAG-K v2.0에서 산출한 CR은 적절할 것으로 보인다.

HAG-K v2.0에서 산출한 REIG를 한국 난청인의 선호이득 (Bang \& Lee, 2020)과 비교한 Figure 2를 보면 $2.0 \mathrm{kHz}$ 이하 의 주파수에서 REIG65 및 REIG80은 비슷하게 나타났다. 그 러나 HAG-K v2.0의 REIG50가 선호이득에 비해 낮게 나타났 다. 즉, HAG-K v2.0의 CT가 높게 나타나 Han \& Lee(2020) 의 30 백분위수의 SPL을 뒷받침한 것으로 볼 수 있다.

본 연구의 HAG-K v2.0과 선행연구인 HAI-v1(Jin et al., 2017; Han et al., 2017)의 REIG를 입력 SPL 65 dB를 중심으 로 NAL-NL2 및 DSL5.0과 비교하여 살펴보면 다음과 같다. 입력 SPL $65 \mathrm{~dB}$ 에 대한 REIG는 HAI-v1의 경우 $0.5 \mathrm{kHz}$ 이 하와 $4.0 \mathrm{kHz}$ 이상에서는 NAL-NL2와 DSL5.0에 비해 낮게 나타났으나, $1.0 \mathrm{kHz}$ 와 $2.0 \mathrm{kHz}$ 에서는 $\mathrm{HAG}-\mathrm{K}$ v2.0이 높게 나타났다. 그러나 HAG-K v2.0에서는 HTL이 $60 \mathrm{~dB}$ HL일 때 입력 SPL $65 \mathrm{~dB}$ 에 대한 REIG는 $0.75 \mathrm{kHz}$ 이하와 $4.0 \mathrm{kHz}$ 이 상에서는 NAL-NL2 및 DSL5.0이 높게 나타났으나, $1.0 \mathrm{kHz}$ 와 $3.0 \mathrm{kHz}$ 에서는 NAL-NL2와 비슷하게 나타났다. 그리고 $\mathrm{HAG}-\mathrm{K}$ v2.0과 $\mathrm{HAI}-\mathrm{v} 1$ 의 CT와 $\mathrm{CR}$ 을 비교해 보면 CT는 HAG-K v2.0이 $60 \mathrm{~dB}$ SPL 부근으로 $31 \mathrm{~dB}$ SPL 부근의 HAI$\mathrm{v} 1$ 에 비해서 높게 나타났으며, $\mathrm{CR}$ 은 대부분의 주파수에서
HAI-v1이 HAG-K v2.0에 비해 높게 나타나 차이를 보였다.

본 연구에서는 한국어 대화음레벨과 스펙트럼, HTL에 따른 $\mathrm{MCL}$ 과 $\mathrm{UCL}$ 의 변화와 선호이득 등 한국어의 음향적 특징과 한국인의 심리음향적 특성을 고려하여 한국형 보청기적합공식 $\mathrm{HAG}-\mathrm{K}$ v2.0을 개발하여 청능재활 현장에서 보청기의 효과적 인 조절과 한국 난청인의 어음인지도, 의사소통 능력 그리고 보 청기의 만족도를 개선하고자 하였다. Souza(2002), Jeong \& Lee(2018) 등이 비선형 증폭기의 해제시간은 어음 및 잡음의 인지에 영향을 준다고 하였다. 하지만 대부분의 보청기 제조사 에서 해제시간을 다양하게 설정하며, 한국어음의 인지에 미치 는 영향에 대한 연구 또한 부족하여 한국형 보청기적합공식의 초기 버전인 HAG-K v2.0에서는 해제시간을 고려하지 않았다.

본 연구에서 보청기적합공식을 산출할 때 적용한 대부분의 선행연구에서는 성인 및 노인을 대상으로 진행하였기 때문에 $\mathrm{HAG}-\mathrm{K}$ v2.0은 아동보다는 성인 또는 노인이 착용하는 보청 기의 이득을 산출할 때 효과적일 것으로 생각한다. 따라서 향 후의 한국형 보청기적합공식 관련 연구에서는 아동, 성인, 노인 등 난청인의 연령, 청각손실의 종류, 형태 및 정도, 개방형과 폐 쇄형 등 보청기의 형태와 환기구의 직경, 한국어음의 인지에 효 과적인 해제시간, 음향피드백의 활성화 여부, 채널의 수 그리고 난청인의 생활환경을 고려한 보청기 이득을 산출하기 위하여 실생활에서의 대화음과 소음의 강도 및 스펙트럼 등에 대한 연 구가 필요하다. 아울러 다양한 환경에서 보청기의 음질, 착용 만족도, 어음인지도 등의 평가를 통하여 HAG-K v2.0을 체계 적으로 검증하고 수정 및 보완한다면 한국 난청인이 착용하는 보청기의 전기음향적 조절과 의사소통 능력의 개선에 도움을 줄 수 있을 것이다.

중심 단어 : $\mathrm{HAG}-\mathrm{K} v 2.0$ ·보청기·적합공식·한국인·난청인.

\section{Ethical Statement}

This study was approved by the Institutional Review Board of Hallym University of Graduate Studies (IRB \#HUGSAUD674235).

\section{Acknowledgments}

N/A

\section{Declaration of Conflicting Interests}

There is no conflict of interests.

\section{Funding}

This research was completed while being supported by National Research Foundation of Korea (2018R1A2B6001986).

\section{Author Contributions}

Conceptualization: Kyoungwon Lee. Data curation: Kyoungwon Lee, Hyeryeong Jo. Formal analysis: Kyoungwon Lee. Funding acquisition: Kyoungwon Lee. Investigation: Kyoungwon Lee. Methodology: Kyoungwon Lee. Project administration: Kyoungwon Lee. Writing_original draft: 
Kyoungwon Lee. Writing — review \& editing: all authors. Approval of final manuscript: all authors.

\section{ORCID iDs}

Kyoungwon Lee

Soohyun Ahn

Hyeryeong Jo

https://orcid.org/0000-0002-1297-6436

https://orcid.org/0000-0002-7117-2331

https://orcid.org/0000-0002-6631-7815

\section{REFERENCES}

Aazh, H., Moore, B. C. J., \& Prasher, D. (2012). The accuracy of matching target insertion gains with open-fit hearing aids. American Journal of Audiology, 21(2), 175-180.

Bang, E. \& Lee, K. (2020). A study on the preferred real-ear insertion gain of multi-channel hearing aid for the Korean with sensorineural hearing loss. Audiology and Speech Research, 16(2), 85-94.

Barker, C. \& Dillon, H. (1999). Client preferences for compression threshold in single-channel wide dynamic range compression hearing aids. Ear and Hearing, 20(2), 127-139.

Barker, C., Dillon, H., \& Newall, P. (2001). Fitting low ratio compression to people with severe and profound hearing losses. Ear and Hearing, 22(2), $130-141$

Boike, K. T. \& Souza, P. E. (2000). Effect of compression ratio on speech recognition and speech-quality ratings with wide dynamic range compression amplification. Journal of Speech, Language, and Hearing Research, 43(2), 456-468.

Byrne, D. \& Dillon, H. (1986). The National Acoustic Laboratories' (NAL) new procedure for selecting the gain and frequency response of a hearing aid. Ear and Hearing, 7(4), 257-265.

Byrne, D., Dillon, H., Ching, T., Katsch, R., \& Keidser, G. (2001). NAL-NL1 procedure for fitting nonlinear hearing aids: characteristics and comparisons with other procedures. Journal of the American Academy of Audiology, 12(1), 37-51.

Cox, R. M. (1995). Using loudness data for hearing aid selection: The IHAFF approach. The Hearing Journal, 48(2), 10, 39-44.

Han, W., Lee, J., Kim, J., Lee, K., \& Kim, D. (2017). Preferred Compression Threshold and Release Time in Quiet and Noisy Conditions for Elderly Korean Hearing Aid Users. Journal of Audiology and Otology, 21(3), 133-139.

Han. Y. K. \& Lee, K. (2020). A study on the Korean conversation speech level and spectrum in sound-treated environment. Audiology and Speech Research, 16(2), 133-139.

International Electrotechnical Commission. (2012). Electroacoustics-Hearing Aids-Part 15: Methods for Characterising Signal Processing in Hear- ing Aids with a Speech-Like Signal (IEC 60118-15:2012). Geneva: International Electrotechnical Commission.

Jeong, J. \& Lee, K. (2018). Changes of non-sense syllabic word scores and preferences as a function of release time on multi-channel hearing aids. Audiology and Speech Research, 14(4), 250-258.

Jin, I. K., Lee, J., Lee, K., Kim, J., Kim, D., Sohn, J., et al. (2016). The Band-Importance Function for the Korean Standard Sentence Lists for Adults. Journal of Audiology and Otology, 20(2), 80-84.

Jin, I. K., Lee, K., Kim, J., Kim, D., Sohn, J., \& Lee, J. (2017). Comparison of a hearing aid fitting formula based on Korean acoustic characteristics and existing fitting formulae. Audiology and Speech Research, 13(3), 216-221.

Johnson, E. E. \& Dillon, H. (2011). A comparison of gain for adults from generic hearing aid prescriptive methods: impacts on predicted loudness, frequency bandwidth, and speech intelligibility. Journal of the American Academy of Audiology, 22(7), 441-459.

Keidser, G., Dillon, H., Flax, M., Ching, T., \& Brewer, S. (2011). The NALNL2 Prescription Procedure. Audiology Research, 1(1), e24.

Kiessling, J., Schubert, M., \& Archut, A. (1996). Adaptive fitting of hearing instruments by category loudness scaling (ScalAdapt). Scandinavian Audiology, 25(3), 153-160.

Killion, M. \& Fikret-Pasa, S. (1993). The 3 types of sensorineural hearing loss: Loudness and intelligibility considerations. The Hearing Journal, 46(11), 31-36.

Kim, S. \& Lee, K. (2019). Changes of Consonant Recognition and Sound Quality as a Function of Compression Threshold on Multi-Channel Hearing Aids. Audiology and Speech Research, 15(1), 23-29.

Lee, K. W. \& Kim, J. S. (2011). Suggestion of hearing aid gain for Korean hearing impaired (HAG-K). Audiology and Speech Research, 7(2), 119-123.

Lee, K. W. \& Kim, J. S. (2012). The study of frequency importance function of the Korean monosyllabic words. Audiology and Speech Research, 8(1), 24-33.

Lippmann, R. P., Braida, L. D., \& Durlach, N. I. (1981). Study of multichannel amplitude compression and linear amplification for persons with sensorineural hearing loss. The Journal of the Acoustical Society of America, 69(2), 524-534.

Noh, H. \& Lee, D. H. (2012). Cross-language identification of long-term average speech spectra in Korean and English: toward a better understanding of the quantitative difference between two languages. Ear and Hearing, 33(3), 441-443.

Park, Y. J. \& Lee, K. W. (2013). A Changes of Loudness Growth as a Function of Hearing Threshold Level in Adults with Normal and Sensorineural Hearing Loss. Audiology and Speech Research, 9(1), 25-32.

Souza, P. E. (2002). Effects of compression on speech acoustics, intelligibility, and sound quality. Trends in Amplification, 6(4), 131-165. 